V.M. Kyrylenko, K.V. Kyrylenko, M.O. Budko, P.L. Denysiuk

\title{
Reasoning of additional diagnostic parameters for electric insulation diagnostics by absorption methods
}

The aim of this work is to analyze the inadequacies of the diagnostic parameters, in particular the absorption and polarization coefficients, which are manifested in their integral character and dependence on the ratio of values of several elements of the equivalent scheme of insulation replacement. This article contains the results of theoretical investigation of the extreme nature of the absorption diagnostic parameters, which leads to unambiguity of the diagnostics procedure. The ways of partial adjustment of this unambiguity have been proposed. Methodology. To determine the extremality of the absorption coefficients depending on the absorption time, absorption capacity and resistance, as well as the leakage resistance, the usual method of investigating the functions was used, detailed calculations have been obtained by using MATLAB software. Results. Has been shown that the ambiguity of diagnostic results is caused by the contradiction of the integral character of the diagnostic parameters and the local character of the isolation failures, in particular breakdown, by ambiguous dependence of the diagnostic parameters on the values of the elements of the insulation replacement scheme and the extremal nature of the diagnostic parameters. Based on the general expression describing all currently used absorption coefficients, it is shown that they all have an extremum, the value of which depends on the parameters of the insulation substitution scheme and the time interval between the measurements of the absorption current. The dependence of the extreme value of the absorption and polarization coefficients on the parameters of the insulation substitution scheme has been established. Has been shown that to eliminate the ambiguity caused by the extremity of the absorption coefficients, it is necessary to introduce additional diagnostic parameters, such as the ratio of leakage resistance to absorption resistance, as well as the critical value of the absorption time constant. Originality. The detailed analysis of the reasons of ambiguity of electric insulation technical diagnostics by absorption methods has been carried out. A method for eliminating the ambiguity caused by the extremity of the absorption coefficients has been proposed. Practical significance. To eliminate the ambiguity caused by the extremity of the absorption coefficients, additional diagnostic parameters are proposed - the ratio of leakage resistance to the absorption resistance and critical values of the absorption time constant. The applying of these parameters with the absorption coefficients will more adequately assess the technical condition of insulation. References 15, tables 2, figures 4.

Key words: non-destructive insulation diagnostics, absorption methods of insulation diagnostics, diagnostic parameters of insulation, dielectric absorption ratio, absorption index, polarization index.

В статті представлено результати аналізу екстремального характеру $і$ зумовленої ним неоднозначності залежності абсорбиійних коефіцієнтів від сталої часу абсорбиії, а також залежності їх значень від відношення наскрізного опору ізоляиії до ії абсорбичійного опору. Розраховано максимальні значення коефічієнтів абсорбиії і поляризачії, а також сталої часу абсорбиії, що відповідає їм, для різних значень відномення вказаних вище опорів. Обтрунтована можливість використання відношення наскрізного $і$ абсорбційного опорів та абсорбиійної сталої часу в якості додаткових діагностичних параметрів для усунення неоднозначності, пов'язаної з екстремальністю коефіцієнтів абсорбиї $i$ поляризачії. Бібл. 15 , табл. 2 , рис. 4.

Ключові слова: неруйнівні методи діагностування електричної ізоляції, абсорбційні методи діагностування ізоляції, діагностичні параметри ізоляції, ємнісний і омічний коефіцієнти абсорбції, коефіцієнти абсорбції і поляризації.

В статье представлень результать анализа экстремального характера и обусловленной им неоднозначности зависимости абсорбционных коэффициентов от постоянной времени абсорбциии и зависимости их значений от отномения сквозного сопротивления изоляции $к$ ее абсорбционному сопротивлению. Рассчитаны максимальные значения коэффициентов абсорбичи и поляризации, а также постоянных времени абсорбции, которые соответствуют им, для различных значений отношения указанных выле сопротивлений. Обоснована возможность использования отношения сквозного и абсорбционного сопротивлений и абсорбиионной постоянной времени в качестве дополнительных диагностических параметров для устранения неоднозначности, связанной с наличием максимумов коэффициентов абсорбции и поляризации. Библ. 15 , табл. 2 , рис. 4.

Ключевые слова: неразрушающие методы диагностирования электрической изоляции, абсорбционные методы диагностирования изоляции, диагностические параметры изоляции, емкостной и омический коэффициенты абсорбции, коэффициенты абсорбции и поляризации.

Introduction. To ensure efficient and trouble-free operation of electrical engineering and electrical power equipment, periodic or continuous monitoring of its technical condition is carried out using destructive and non-destructive electrical methods of control and testing. Non-destructive methods include the use of electrophysical and dielectric characteristics, their dependencies on the intensity of the electric field and external factors or their relative values at different values of the parameters of the active factors.

To assess the technical condition of electrical insulation in practice they often use the results of its non- destructive diagnosis by the values of electrical resistance of insulation and the characteristics of the absorption current flowing through the insulation when connected to DC voltage. These methods are based on the generalized equivalent dielectric circuit (Fig. 1).

The advantages of the generalized equivalent circuit of inhomogeneous dielectric include transparency of interpretation of the physical content of its elements, their direct connection with physical processes in insulation of inhomogeneous dielectrics which determine its performance properties and durability.

(c) V.M. Kyrylenko, K.V. Kyrylenko, M.O. Budko, P.L. Denysiuk 
The elements of the generalized equivalent dielectric circuit include:

- geometric capacitance $C_{g}$ which reflects the capacitance associated with the rapid processes of electronic and ionic polarization;

- through resistance $R_{n}$, i.e. the steady value of the resistance of the dielectric to the flow of direct current;

- absorption capacitance $C_{a}$ which is responsible for the slow processes of migratory polarization due to the accumulation of free charges within the dielectric regions with different electrophysical properties or in the electrode regions;

- absorption resistance $R_{a}$ which is introduced to correctly reflect the inertial properties of migratory polarization.

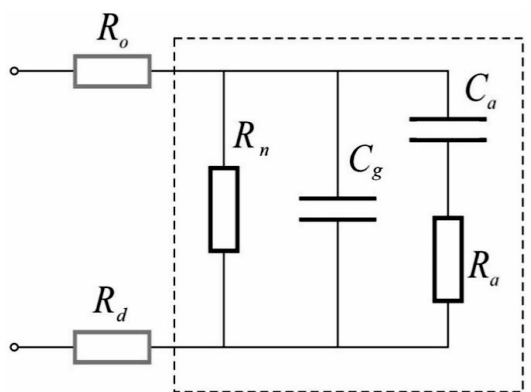

Fig. 1. Generalized equivalent insulation circuit and elements of the measurement circuit

In addition, Fig. 1 shows the circuit elements:

- $R_{o}$ - limiting resistance which is introduced into the measuring circuit to form the exponential charge current of the geometric capacitance;

- $R_{d}$ - resistance of the sensor to measure the voltage that corresponds to the absorption current through the dielectric.

In order for them not to affect the diagnostic results, the resistance value of these resistors must be significantly less than the resistance value of the dielectric leakage.

In the general case, the inhomogeneous dielectric's circuit may contain several $C_{a}-R_{a}$ circuits corresponding to the absorption processes with time constants of different types of migratory polarization. Note that the relaxation polarization when using the absorption and polarization coefficients is not taken into account because the moments of time at which the absorption current is measured to calculate the values of these parameters significantly exceed the time constants of relaxation processes.

Review of the state of absorption methods for diagnosing electrical insulation. Absorption diagnostic methods are recommended as normative for diagnosing insulation of transformers, synchronous generators, compensators, collector exciters and AC motors [1] Modern scientific research of absorption methods and their use relate to diagnosing the insulation condition of rotating electric machines [2, 3], low-voltage and highvoltage cables [4-7], power transformers [8-10].

In technical diagnostics, two types of absorption coefficients are used - ohmic and capacitive coefficients, as well as coefficients determined by the ratio of absorption current values at different points in time, the method of restored voltage and its modern varieties, and nonlinearity of absorption and restored voltage characteristics.

The ohmic absorption coefficient is equal to the ratio of the values of the absorption current or effective insulation resistance, measured after 15 and $60 \mathrm{~s}$ for currents or after 60 and $15 \mathrm{~s}$ for resistances:

$$
k_{a}=\frac{i_{15}}{i_{60}}=\frac{R_{60}}{R_{15}}=\frac{1+\frac{R_{n}}{R_{a}} \exp \left(-\frac{60}{\tau_{a}}\right)}{1+\frac{R_{n}}{R_{a}} \exp \left(-\frac{15}{\tau_{a}}\right)} .
$$

In addition to the ohmic absorption coefficient, they now use the polarization coefficient $k_{p}$ with the values of the absorption current reference time of 60 and $600 \mathrm{~s}$, the dielectric absorption ratio $R_{30} / R_{15}$ and the polarization index $R_{60} / R_{30}$, the dielectric discharge coefficient, and the insulation state coefficient determined by the two, taken at the initial section of the absorption current at 0.06 and $0.1 \mathrm{~s}$, the charge of the geometric capacitance and the time interval between samples:

$$
k_{c i}=\frac{i_{0,06}-i_{0,1}}{\Delta t \cdot q_{g}}=\frac{i_{0,06}-i_{0,1}}{0,04 q_{g}} .
$$

The capacitive absorption coefficient is determined by the ratio of the maximum value of the restored voltage $U_{r \max }$ to the charging voltage $U_{0}$ :

$$
k_{c}=\frac{U_{r \max }}{U_{0}}=\frac{C_{a}}{C_{a}+C_{g}} .
$$

Restored voltage occurs on the insulation, if after a full charge it is disconnected from the voltage source, short-circuited for a short period of time to discharge the geometric capacity, and then allow the absorption tank to charge geometric one, the voltage on which will increase from zero to maximum, and then fall to zero due to the discharge due to the through resistance.

A variation of the capacitive absorption coefficient is the dispersion coefficient, which is determined by charging the insulation capacitance with a short rectangular pulse of duration $\tau_{1}$ of voltage $U_{0}$ and measuring the voltage $U_{d}$ on it after disconnection from the voltage source after a time interval $\tau_{2} \gg \tau_{1}$ when the introduced charge is redistributed between the geometric and absorption capacitances:

$$
D=\frac{U_{0}}{U_{0}-U_{d}}=\frac{C_{g}}{C_{a}}=\frac{1-k_{c}}{k_{c}} .
$$

The use of capacitive and ohmic absorption coefficients to assess the state of electrical insulation has significant disadvantages: first, they are integral characteristics of insulation; secondly, they are determined by the ratio of the values of several elements of the equivalent dielectric circuit; third, they do not give a complete picture of the processes of insulation degradation. Let's consider these issues in more detail.

As follows from (1), the values of the absorption coefficient depend on the ratio of through resistance and absorption resistance and on the absorption constant time which are integral indicators because they are averaged over the entire volume of insulation. Therefore, this 
criterion can be used only to assess the general condition of the insulation, such as more or less uniform moisture or caused by its aging general deterioration of electrophysical characteristics and an increase in the probability of failure.

In addition, all coefficients determined by the ratio of the two values of the absorption current, as will be shown below, are extreme values and their criteria can be inherent in both wet and aged insulation and homogeneous insulation, in which absorption processes are very weak.

The capacitive coefficient according to (2) is characterized by the ratio of geometric and absorption capacitances, which are also integral characteristics of insulation, partially characterizes the heterogeneity of insulation and its growth during aging. However, it in general does not provide information on the nature of the resistivity distribution and resistive components of the equivalent circuit, which are responsible for thermal aging and thermal breakdown of the dielectric, and also gives an idea only of the intensity of volume migration or nearelectrode polarizations without specifying its characteristics, such as time constant of migratory polarization. In addition, the value $U_{r \max } / U_{0}$ will depend on the ratio $R_{n} / R_{a}$ because this ratio determines the voltage that can occur on the parallel through resistance $R_{n}$ the geometric capacity $C_{g}$, and therefore the capacitive absorption coefficient will be only the limit value for the ratio $U_{r \max } / U_{0}$.

Further improvements of absorption methods based on restored voltage are actively considered in the literature for the purpose of more adequate technical diagnostics of electrical insulation [11-13]. When using the method of restored voltage, as diagnostic parameters of insulation it is proposed to use the ratio of the maximum value of the restored voltage to the charging one, the initial rate of increase of the restored voltage, the time of reaching the maximum value of the restored voltage, the maximum value of the restored voltage, the coefficients of nonlinearity of the restored voltage, the time constant of the self-discharge, but in this article the method of recharged voltage will not be considered.

Taken into account the prevalence of absorption methods, most modern domestic and foreign megohmmeters allow not only to measure the insulation resistance, but also automatically calculate the absorption coefficient and record data to calculate the polarization coefficient. Even more detailed processing of the absorption curve, including the method of recharge voltage, is offered in specialized diagnostic systems.

However, it should be noted that with various proposals for the selection of diagnostic procedures and parameters and fairly intensive publication of the results of the use of absorption methods for diagnostic purposes in domestic and foreign literature, quite serious problems remain the choice of good condition when using appropriate diagnostic parameters and interpretation of processes occurring in isolation, based on changes in specific diagnostic parameters over time, and at the same time the results obtained to assess the state of electrical insulation.

The main factor that significantly reduces the prognostic potential of absorption methods is the irreparable contradiction between the integral nature of diagnostic parameters and the local nature of the breakdown, as a catastrophic process of insulation failure. Absorption methods can give an idea of the general state of insulation due to thermal aging and other processes that lead to the deterioration of the general state of insulation, but they are not effective for predicting breakdown. The possibility of breakdown is determined by the characteristics of the insulation in a very limited volume, which is hundreds of thousands of parts of the total volume, and therefore the value of the integral characteristics is not affected.

Promising in the improvement of absorption methods are works in which methods of determining the individual values of the parameters of the equivalent insulation substitution circuit are considered [14], but they also do not solve this problem. In addition, the diagnostic parameters are transient in time, which leads to additional errors in their use to determine the technical condition [15].

In addition, even the patterns of change of diagnostic parameters depending on the values of the parameters of the equivalent insulation circuit have not been systematically studied, although this dependence leads to ambiguity of technical condition criteria and reduces their prognostic ability. As an example, we can cite the extremity of the absorption and polarization coefficients, which, as shown below, will be close to unity also in highly humid and almost homogeneous insulation. Therefore, there is a need to eliminate this ambiguity.

The goal of this article is to study the extremity of ohmic absorption coefficients and to substantiate additional diagnostic parameters to eliminate the ambiguity of absorption and polarization coefficients associated with the presence of a maximum in the dependencies of these coefficients on the absorption time constant.

Analysis of the extremity of the absorption coefficients. We will perform this analysis using a generalized equivalent circuit of an inhomogeneous dielectric (see Fig. 1), which is the basis of absorption methods for diagnosing electrical insulation.

According to the definition, ohmic absorption coefficients, i.e. absorption coefficients, polarization, dielectric absorption ratio and polarization index, are equal to the ratio of the insulation resistances of the product, measured after time equal to $t_{1}$ and $t_{2}$, after applying a constant voltage [1]:

$$
k_{a}=\frac{R_{t_{1}}}{R_{t_{2}}}=\frac{1+\frac{R_{n}}{R_{a}} \exp \left(-\frac{t_{1}}{\tau_{a}}\right)}{1+\frac{R_{n}}{R_{a}} \exp \left(-\frac{t_{2}}{\tau_{a}}\right)},
$$

where $\tau_{a}=C_{a} \cdot R_{a}$ is the absorption time constant.

We show that all absorption coefficients determined by the ratio of the two values of the absorption current are extreme values and their criteria can be inherent in both wet or aged insulation and homogeneous insulation, in which the absorption processes are very weak.

Consider in general form expression (3), which characterizes the absorption coefficients of insulation, 
denoting $x=R_{n} / R_{a}$, and perform its study on extremes, using as independent variables the ratio of the through resistance to the absorption $x$ and the time constant of the absorption process $\tau_{a}$. The derivative with respect to $x$ of the expression for the absorption coefficient is equal to

$$
\frac{d k_{a}}{d x}=\frac{\exp \left(-\frac{t_{2}}{\tau_{\mathrm{a}}}\right)-\exp \left(-\frac{t_{1}}{\tau_{\mathrm{a}}}\right)}{\left(1+x \exp \left(-\frac{t_{1}}{\tau_{\mathrm{a}}}\right)\right)^{2}}
$$

According to (4), the extremum condition $\mathrm{d} k_{a} / \mathrm{d} x=0$ is satisfied only when $x \rightarrow \propto$, i.e. at $R_{n} / R_{a} \rightarrow \propto$.

From this it follows that $\mathrm{d} k_{a} / \mathrm{d} x$ is an increasing function from 1 with saturation by function $R_{n}$ at $R_{a}=$ const, or a similar function of the ratio $R_{n} / R_{a}$ and has a one-sided maximum at infinity, the value of which depends on the absorption constant $\tau_{a}$ and the moments of reference time of the absorption current $t_{1}$ and $t_{2}$.

For the derivative with respect to $\tau_{a}$ we have:

$$
\frac{\mathrm{d} k_{a}}{\mathrm{~d} \tau}=\frac{\frac{t_{2}}{\tau_{a}^{2}} x \exp \left(-\frac{t_{2}}{\tau_{a}}\right)+\frac{t_{2}}{\tau_{a}^{2}} x^{2} \exp \left(-\frac{t_{1}+t_{2}}{\tau_{a}}\right)-\frac{t_{1}}{\tau_{a}^{2}} x \exp \left(-\frac{t_{1}}{\tau_{a}}\right)-\frac{t_{1}}{\tau_{a}^{2}} x^{2} \exp \left(-\frac{t_{1}+t_{2}}{\tau_{a}}\right)}{\left(1+x \exp \left(-\frac{t_{1}}{\tau_{\mathrm{a}}}\right)\right)^{2}} .
$$

Extreme condition $\mathrm{d} k_{a} / \mathrm{d} x=0$ gives two possibilities. The first one is $\tau_{a \max }=\infty$ and $R_{n} / R_{a} \rightarrow \infty$.

$$
t_{2} \exp \left(-\frac{t_{2}}{\tau_{a \text { max }}}\right)+t_{2} x \exp \left(-\frac{t_{1}+t_{2}}{\tau_{a \text { max }}}\right)-t_{1} \exp \left(-\frac{t_{1}}{\tau_{a \text { max }}}\right)-t_{1} \exp \left(-\frac{t_{1}+t_{2}}{\tau_{a \text { max }}}\right)=0
$$

This equation after simplification has the form

$$
\frac{t_{1} \exp \left(-\frac{t_{2}}{\tau_{a \max }}\right)+t_{2} x \exp \left(-\frac{t_{1}}{\tau_{a \max }}\right)}{t_{2}-t_{1}}=x=\frac{R_{n}}{R_{a}} \text {. }
$$

Thus, each coefficient, which is determined by the ratio of two values of the absorption current, according to (5) has a maximum, the position of which is determined by the values of the absorption time constant $\tau_{a \max }$, i.e. the product of absorption resistance $R_{a}$ and capacitance $C_{a}$, through resistance to absorption one ratio $R_{n} / R_{a}$, as well as the timing of the values of the absorption current $t_{1}$ and $t_{2}$. The position of the maximum will affect the values of the diagnostic parameters at this point and lead to a change in the set of values of the parameters of the equivalent circuit, which correspond to the critical value of the diagnostic parameter, which complicates the interpretation of insulation control results.

Analysis of the influence of substitution circuit parameters on absorption coefficients. Let us consider in more detail the influence of the parameters of the generalized equivalent insulation circuit on the absorption coefficients on the example of the absorption and polarization coefficients.

In the normative literature [1] when evaluating the insulation humidity of electrical engineering and electrical power equipment, as the critical value of the ohmic absorption coefficient $k_{a}=1.3$ is often taken. If $k_{a}$ is less, the insulation is considered wet. In the general case, the critical values of $k_{a}$ can be in the range of $1.2-1.6$. Note that the accepted interpretation of $k_{a}$ as a criterion for wetting the material is not entirely accurate due to the significant dependence of its value on $C_{a}, R_{a}$ and the absorption constant.

Indeed, the ambiguity in the interpretation of diagnostic results is due to the fact that the dependence of the absorption coefficient has a maximum not only on the absorption constant, but also separately from the absorption capacitance at a constant value of absorption resistance, and from the absorption resistance at a constant value of absorption capacitance. Therefore, we note that almost no attention is paid: for homogeneous insulation with non-blocking electrodes, the absorption capacitance $C_{a}$, and hence the absorption time constant $\tau_{a}$, must be close to zero, and the absorption coefficient $k_{a}$ according to (1) will be close to 1 . That is, both for an ideal dielectric when the absorption time constant is close to zero due to a small value of the absorption capacitance, and for a significantly humidified dielectric when a small value of the absorption constant is due to a small value of the absorption resistance, the absorption coefficient $k_{a} \approx 1$. This means that the absorption coefficient dependence on the absorption constant is extreme, which is indeed the case, as shown in Fig. 2. As can be seen from Fig. 2, in the region of small values of $\tau_{a}$ there is a rather sharp decrease in the absorption coefficient with decreasing $\tau_{a}$, and with increasing $\tau_{a}$ after the maximum its gradual decline.

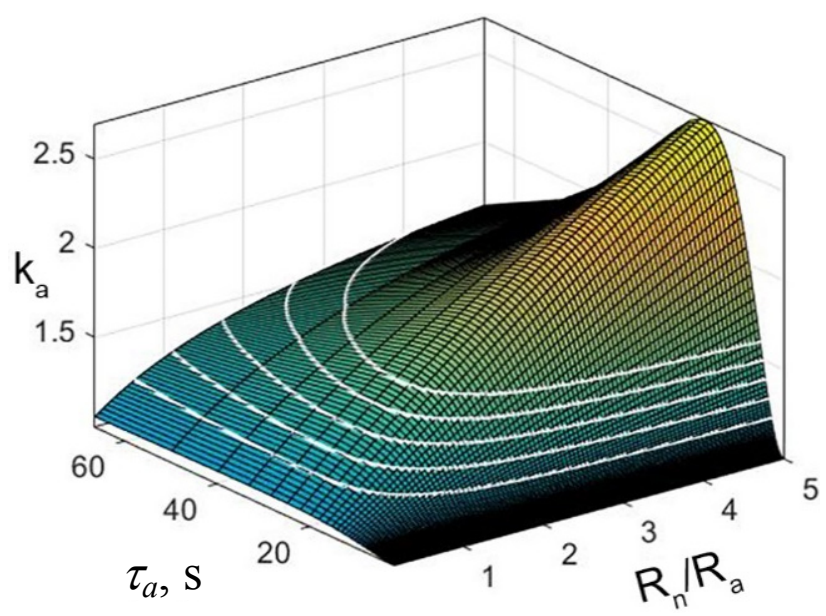

Fig. 2. Dependence of the absorption coefficient on the absorption time constant and the ratio of through resistance to absorption one. The contours for the values of the absorption coefficient $1.2-1.6$ are shown (bottom to top) 
The absorption coefficient $k_{a}$ at $\tau_{a}=$ const has a constant value, as shown by the calculation, only at a certain ratio of $R_{n}$ and absorption characteristics. As an example Fig. 2 shows a cross section of the graph by planes $k_{a}=[1.2 ; 1.3 ; 1.4 ; 1.5 ; 1.6]$ which corresponds to the values of $k_{a}$ which are taken as a criterion in assessing the insulation of electrical engineering and electrical power equipment.

The extreme values of $k_{a}$ and time constants corresponding to them are given in Table 1 . The maximum absorption coefficient $k_{a}$ depending on $\tau_{a}$ takes place at a given ratio $R_{n} / R_{a}$ in the range $\tau_{a}=7.5-33.5 \mathrm{~s}$. Two values of the absorption time constant $\tau_{a}$ correspond to the same value of $k_{a}$ outside the maximum at $R_{n} / R_{a}=$ const. For example, at the ratio $R_{n} / R_{a}=1$ critical value $k_{a}=1.3$ correspond to the values $\tau_{a}=13.1 \mathrm{~s}$ and $\tau_{a}=59 \mathrm{~s}$, and at $R_{n} / R_{a}=10-$ values $\tau_{a}=4.25 \mathrm{~s}$ and $\tau_{a}=152 \mathrm{~s}$

Table 1

\begin{tabular}{|c|c|c|c|c|c|c|c|c|c|}
\hline Parameter & $R_{n} / R_{a}$ & 0,0001 & 0,001 & 0,01 & 0,1 & 1 & 10 & 100 & 1000 \\
\hline \multirow{2}{*}{$k_{a}$} & $\tau_{\text {max }} \mathrm{s}$ & 32,44 & 32,44 & 32,345 & 31,46 & 25,88 & 16,27 & 10,42 & 7,49 \\
\cline { 2 - 11 } & $k_{a \max }$ & 1 & 1,0005 & 1,0047 & 1,0465 & 1,42 & 3,98 & 18,78 & 102,09 \\
\hline \multirow{2}{*}{$k_{p}$} & $\tau_{\text {max }} \mathrm{s}$ & 234 & 234 & 230 & 226 & 190 & 125 & 65,5 & 55 \\
\cline { 2 - 10 } & $k_{p \max }$ & 1 & 1,0007 & 1,007 & 1,07 & 1,66 & 6,64 & 362,9 & 2841 \\
\hline
\end{tabular}

Calculations at different ratios of through and absorption resistances show that the value of the time constant $\tau_{a}$, which corresponds to the maximum value of $k_{a}$, is almost constant at $R_{n} / R_{a}<1$ and gradually decreases at $R_{n} / R_{a}>1$, when the absorption coefficient begins to increase markedly. As for the polarization coefficient $k_{p}$, all the qualitative regularities that take place for the absorption coefficient are preserved, but the quantitative characteristics are shifted towards larger values (Table 1). For both coefficients, the maximum value of the coefficients goes to infinity at $R_{n} / R_{a} \rightarrow \propto$ and zero $\tau_{a}$. At the same time, when the value of $R_{n} / R_{a}$ is zero, the maximum value of the absorption coefficient takes place at $\tau_{a}=32.46 \mathrm{~s}$, and for the polarization coefficient $k_{p}$ at $\tau_{a}=234 \mathrm{~s}$.

Depending on the through resistance, the absorption coefficient increases monotonically with saturation from 1 to $\exp \left(\left(t_{2}-t_{1}\right) / \tau_{a}\right)$, where $t_{1}$ and $t_{2}$ are the time of resistance measurement after voltage application, with increasing through resistance to infinity. It should be borne in mind that $\exp \left(\left(t_{2}-t_{1}\right) / \tau_{a}\right)$ at $t_{2}-t_{1}=$ const exponentially decreases with increasing $\tau_{a}$, and therefore the saturation level $k_{a}$ will be quite different at different absorption resistances, which is shown in Fig. 3, where the maximum value of the absorption coefficient can reach 60 at small ratios $R_{n} / R_{a}$ and $t_{2}-t_{1}=60 \mathrm{~s}$. Theoretically, at larger values of the difference $t_{2}-t_{1}$, the maximum value of the absorption coefficient can reach several hundred.

The critical ratio of leakage resistance to absorption resistance occurs at certain values of the absorption constant (Fig. 4), which are also a function of the resistance ratio $R_{n} / R_{a}$. Note that the maximum values of the absorption time constant $\tau_{a \max }$ for the polarization coefficient are much larger compared to its values for the absorption coefficient in the same range of values $R_{n} / R_{a}$.

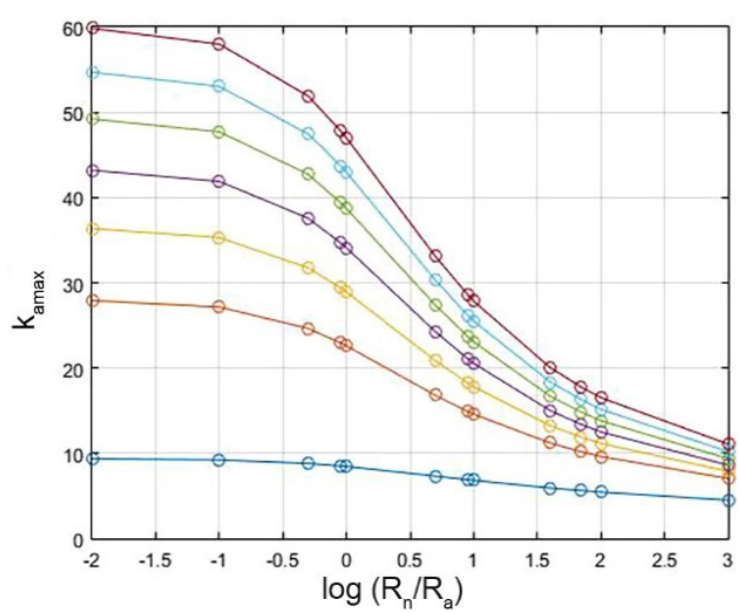

Fig. 3. Dependence of the maximum value of the absorption coefficient $k_{a \max }$ on $\lg \left(R_{n} / R_{a}\right)$ at values of a difference of moments of time of measurement of absorption current $t_{2}-t_{1}: 0.1,10,20,30,40,50,60 \mathrm{~s}$ (bottom to top)

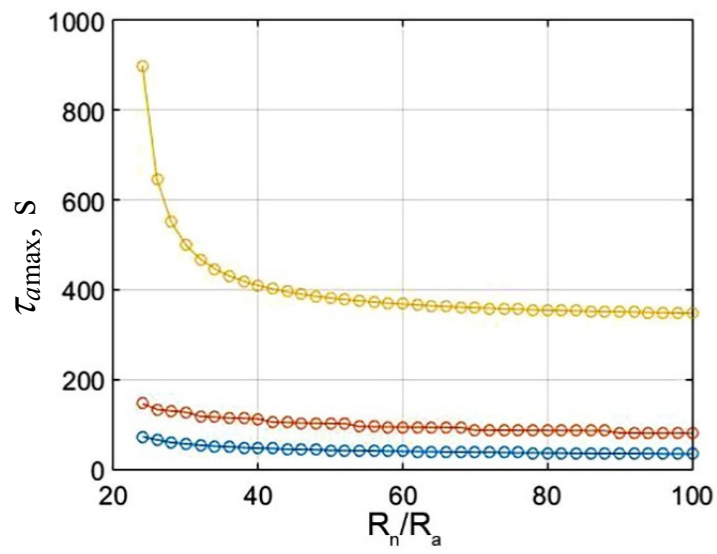

Fig. 4. The values of the absorption constant $\tau_{a \max }$ corresponding to the extremum of the absorption coefficient (bottom), when $t_{1}=30$ and $t_{2}=120 \mathrm{~s}$, as well as for the polarization coefficient (upper curve) depending on $R_{n} / R_{a}$

Thus, the results of the simulation carried out confirm the ambiguity of the ohmic absorption coefficient and the polarization coefficient as diagnostic parameters. The ambiguity of the dependence of the absorption coefficients on $\tau_{a}$ and the dependence of their values on the ratio of resistances $R_{n} / R_{a}$ leads to the impossibility of unambiguous interpretation of the results because the same value of $k_{a}$ can correspond to material with satisfactory properties and material with low resistance levels. Small values of $\tau_{a}$ are possible both at small values of $C_{a}$ characteristic of a qualitative homogeneous material, and at small values of $R_{a}$ which correspond to the large microdefectivity of individual regions of this material.

For large values of $\tau_{a}$ which occur at large $C_{a}$ and $R_{a}$, the interpretation is the opposite - the material is very inhomogeneous, but not very defective. In addition to this ambiguity, it should also be taken into account that at the same constant value of $\tau_{a}$ increase in $C_{a}$ and corresponding decrease in $R_{a}$ are responsible for deterioration of material properties, and decrease in $C_{a}$ and increase in $R_{a}$ - improvement, and without separate definition of these parameters it is impossible to answer, in which direction the properties of the material change. 
These considerations confirm that the absorption coefficients are quite contradictory and difficult to interpret the results obtained in the process of technical diagnosis of insulation and that they can be effective if used to diagnose this type of insulation of this manufacturer after preliminary tests.

Introduction of an additional diagnostic parameter to eliminate the ambiguity of the absorption coefficients. To increase the diagnostic capacity of the absorption coefficients, which is limited by the presence of a maximum depending on their absorption time constant, it is possible to use an additional diagnostic parameter, in particular the limit value of the ratio $\left(R_{n} / R_{a}\right)_{c r}$.

As follows from Fig. 2, there is the smallest value of the ratio $\left(R_{n} / R_{a}\right)_{c r}$, with a further decrease of which the absorption coefficient will have a value only less than the criterion at any values of the absorption constant. To find the limit values of the ratio $\left(R_{n} / R_{a}\right)_{c r}$ it is necessary to substitute in (3) the criterion value of the absorption coefficient, which will give the equation of the cross section profile corresponding to this value, find the value of the absorption constant

$$
\tau_{a \min }=\frac{t_{2}-t_{1}}{\ln \left(\frac{k_{a} t_{2}}{t_{1}}\right)},
$$

corresponding to the minimum absorption coefficient depending on the resistance ratio $R_{n} / R_{a}$, and then calculate $\left(R_{n} / R_{a}\right)_{c r}$, substituting $\tau_{a \min }$ in the equation:

$$
\left(\frac{R_{n}}{R_{a}}\right)_{c r}=\frac{k_{a}-1}{\exp \left(-\frac{t_{1}}{\tau_{a \text { min }}}\right)-k_{a} \exp \left(-\frac{t_{2}}{\tau_{a \text { min }}}\right)} .
$$

Calculated by (6), (7) the limit values of the ratio $\left(R_{n} / R_{a}\right)_{c r}$ for different values of the absorption and polarization coefficients, and the corresponding values of the absorption time constants corresponding to these values of the coefficients are given in Table 2 .

\begin{tabular}{|l|c|c|c|c|c|c|c|c|c|c|c|}
\multicolumn{1}{|c|}{$\begin{array}{c}\text { The values of } \\
\text { the absorption } \\
\text { coefficient }\end{array}$} & 1,1 & 1,2 & 1,3 & 1,4 & 1,5 & 1,6 & 1,7 & 1,8 & 1,9 & 2,0 \\
\hline \multirow{2}{*}{$k_{a}$} & $\left(R_{n} / R_{a}\right)_{c r}$ & 0,22 & 0,45 & 0,69 & 0,95 & 1,21 & 1,49 & 1,77 & 2,06 & 2,36 & 2,67 \\
\cline { 2 - 12 } & $\tau_{a \min }, \mathrm{s}$ & 30,4 & 28,7 & 27,3 & 26,1 & 25,1 & 24,2 & 23,5 & 22,8 & 22,2 & 21,64 \\
\hline \multirow{2}{*}{$k_{p}$} & $\left(R_{n} / R_{a}\right)_{c r}$ & 0,145 & 0,293 & 0,44 & 0,60 & 0,75 & 0,91 & 1,07 & 1,23 & 1,39 & 1,55 \\
\cline { 2 - 11 } & $\tau_{a \min }, \mathrm{s}$ & 225 & 217 & 210 & 205 & 199 & 195 & 191 & 187 & 183 & 180 \\
\hline
\end{tabular}

If we use the limits values of the absorption or polarization coefficients and the ratio $\left(R_{n} / R_{a}\right)_{c r}$ at the same time, the ambiguity of the diagnosis associated with the presence of a maximum in the absorption coefficients will be overcome.

We also give formulas for determining the limit values of the ratio $\left(R_{n} / R_{a}\right)_{c r}$ depending on the values of the absorption constant that do not correspond to the minimum.

For an absorption coefficient equal to 1.3 , at $20 \mathrm{~s}<\tau_{a}<100 \mathrm{~s}$ for the limit values $\left(R_{n} / R_{a}\right)_{c r}$ we can write a linearized equation

$$
\left(\frac{R_{n}}{R_{a}}\right)_{c r}=0,29+0,0141 \cdot \tau_{a},
$$

and for the polarization coefficient equal to 2 in the region $185 \mathrm{~s}<\tau_{a}<1250 \mathrm{~s}$ accordingly

$$
\left(\frac{R_{n}}{R_{a}}\right)_{c r}=0,215+0,00103 \cdot \tau_{a} .
$$

If the value obtained in the diagnostic test $\left(R_{n} / R_{a}\right)_{c r}$ is less than that calculated by (8), (9), the technical condition of the insulation is not satisfactory.

Note that in this case both $\left(R_{n} / R_{a}\right)_{c r}$, and $\tau_{a}$ should be used as diagnostic parameters. The proposed additional diagnostic parameters are auxiliary, used to eliminate the ambiguity of the main criterion of the absorption or polarization coefficient, and can be applied to the most commonly used critical values of the absorption coefficient $k_{a}=1.3$ and the polarization coefficient $k_{p}=2$. For larger values of the absorption coefficients, it is possible to calculate $\left(R_{n} / R_{a}\right)_{c r}$, and $\tau_{a}$ by the same formulas, but they will correspond to the slightly underestimated limit values of the absorption coefficients.

\section{Conclusions.}

It is shown that the absorption and polarization coefficients are extreme functions of the ratio of through and absorption resistances, absorption constant time, as well as absorption capacitance and resistance separately, which reduces their prognostic capacity and leads to ambiguous interpretation of diagnostic results.

The possibility of introducing an additional diagnostic parameter, which is the ratio of through and absorption resistances $\left(R_{n} / R_{a}\right)_{c r}$ in the minimum line of intersection of the dependence $k_{a}\left(\tau_{a}, R_{n} / R_{a}\right)$ with the plane $k_{a}=$ const, to eliminate the ambiguity associated with the extremity of absorption coefficients, is justified. The limit values of the ratio of through and absorption resistances $\left(R_{n} / R_{a}\right)_{c r}$ for absorption and polarization coefficients in the range of values from 1.1 to 2 is calculated. When obtaining in the process of diagnosing insulation values of the ratio $R_{n} / R_{a}$ less than the limit ones, at any values of absorption constant insulation state will be unsatisfactory.

Formulas for calculating the critical values of the $R_{n} / R_{a}$ ratio at the values of the absorption time constant in the range of $20<\tau_{a}<100$ for $k_{a}=1.3$ and $85<\tau_{a}<1250$ for the polarization coefficient $k_{p}=2$ are proposed, which together can also be used as auxiliary diagnostic parameters for these values of the absorption coefficients.

Conflict of interest. The authors of the article declare no conflict of interest.

\section{REFERENCES}

1. SOU-N-EE-20.302:2007. Testing norms for electrical equipment. Kyiv, DP MOU «Voienne vydavnytstvo Ukrainy «Varta», 2007. 262 p. (Ukr).

2. Noskov V., Mezetsev M., Gavrylenko S., Heiko H. Control and diagnosis of the condition the traction electric drive. Systems of Control, Navigation and Communication, 2021, vol. 1 , no. 63 , pp. 58-61. (Ukr). doi: https://doi.org/10.26906/sunz.2021.1.058.

3. Khamevko O.N., Sushko D.L. Analysis of methods control and diagnostic parameters isolation the traction engine of direct current. Collected scientific works of Ukrainian State University 
of Railway Transport, 2014, no. 147, pp. 152-155. (Ukr). doi: https://doi.org/10.18664/1994-7852.147.2014.75121.

4. Bezprozvannych G.V., Moskvitin E.S., Kyessayev A.G. The absorption characteristics of the phase and zone paperimpregnated insulation of power cable at direct voltage. Electrical Engineering \& Electromechanics, 2015, no. 5, pp. 6368. doi: https://doi.org/10.20998/2074-272X.2015.5.09.

5. Tamus Z.A., Berta I. Application of voltage response measurement on low voltage cables. 2009 IEEE Electrical Insulation Conference, 2009, pp. 444-447. doi https://doi.org/10.1109/EIC.2009.5166387.

6. Bezprozvannych G.V., Moskvitin E.S. Estimation criteria for degree of paper-impregnated insulated power cable ageing. Electrical Engineering \& Electromechanics, 2013, no. 4, pp. 3236. doi: https//doi.org/10.20998/2074-272X.2013.4.05.

7. Naboka B.G., Bezprozvannych A.V., Moscvitin E.S., Bytko M.V., Bytko S.M., Golovan A.A. Diagnostics of power system cable lines on dielectric dissipation factor and impregnatedpaper insulation self-discharge time constant. Electrical Engineering \& Electromechanics, 2011, no. 2, pp. 65-69. doi: https://doi.org/10.20998/2074-272X.2011.2.14.

8. Németh B., Csépes G., Vörös C. Applicability of the dielectric response methods of diagnostics of power transformers: Hungarian experiences. 2011 Electrical Insulation Conference (EIC), 2011, pp. 49-53. doi: https://doi.org/10.1109/EIC.2011.5996114.

9. Sarkar S., Sharma T., Baral A., Chatterjee B., Dey D., Chakravorti S. A new approach for determination of moisture in paper insulation of in-situ power transformers by combining polarization-depolarization current and return voltage measurement results. IEEE Transactions on Dielectrics and Electrical Insulation, 2013, vol. 20, no. 6, pp. 2325-2334. doi: https://doi.org/10.1109/TDEI.2013.6678886.

10. Gavrilă D.E., Ciprian I., Gavrilă H.C. Applying the Recovery Voltage Method (RVM) to Study the Degradation of High Power Transformer Insulation. Advanced Materials Research, 2014, vol. 911, pp. 260-265. doi: https://doi.org/10.4028/www.scientific.net/amr.911.260.

11. Mustafa E., Németh R.M., Afia R.S.A., Tamus Z.Á. Parameterization of Debye Model for Dielectrics Using Voltage Response Measurements and a Benchmark Problem. Periodica
Polytechnica Electrical Engineering and Computer Science, 2021, vol. 65, no. 2, pp. 138-145. doi: https://doi.org/10.3311/ppee.16399.

12. Tamus Z.Á. Combination of voltage response method with non-contact electrostatic voltage measurement to determine the dielectric response of insulating materials. Journal of Physics: Conference Series, 2019, vol. 1322, p. 012042. doi: https://doi.org/10.1088/1742-6596/1322/1/012042.

13. Sun Y., Li Z., Han Y., Suo C. An effective method to avoid charge leakage along the surface in voltage response measurement. Review of Scientific Instruments, 2021, vol. 92, no. 5, p. 055104. doi: https://doi.org/10.1063/5.0051428.

14. Roziskulov S.S. Mykhailiv V.I., Hrabchuk B.L. Transient electromagnetic processes in inhomogeneous electrical isolation of high-voltage cables during its diagnosis by methods of measuring and analyzing the relaxation current and the return voltage. Methods and devices of quality control, 2013, no. 1(30), pp. 84-91. (Ukr). Available at http://194.44.112.13/journals/3328p.pdf (accessed 16 June May 2021).

15. Bezprozvannych G.V., Kostiukov I.A. Error of control of electrical insulation structures by dielectric absorption parameters according to the concept of uncertainty of measurements. Electrical Engineering \& Electromechanics, 2020, no. 1, pp. 47-51. doi: https://doi.org/10.20998/2074272X.2020.1.07.

Received 09.10.2021

Accepted 12.11.2021

Published 03.12.2021

V.M. Kyrylenko ${ }^{1}$, PhD, Associate Professor,

K.V. Kyrylenko ${ }^{1}, P h D$,

M.O. Budko ${ }^{1}, P h D$,

P.L. Denysiuk ${ }^{1}$, PhD, Associate Professor,

${ }^{1}$ National Technical University of Ukraine

«Igor Sikorsky Kyiv Polytechnic Institute»,

37, Prospect Peremohy, Kyiv-56, 03056, Ukraine,

e-mail: vsemychkirg@gmail.com (Corresponding Author)

How to cite this article:

Kyrylenko V.M., Kyrylenko K.V., Budko M.O., Denysiuk P.L. Reasoning of additional diagnostic parameters for electric insulation diagnostics by absorption methods. Electrical Engineering \& Electromechanics, 2021, no. 6, pp. 39-45. doi: https://doi.org/10.20998/2074-272X.2021.6.06. 